http://www.jfas.info

\title{
EFFECT OF ABIOTIC STRESS UNDER LIGHT AND DARK CONDITIONS ON CAROTENOID CONTENT IN PUMPKIN (CUCURBITA MOSHATA) CALLUSES
}

\author{
N. Shahidan ${ }^{1,3, *}$, R. Othman ${ }^{2}$, I. Jaswir ${ }^{1,2}$ and Y. Z. Hasyun-Hashim ${ }^{2}$
}

${ }^{1}$ Kuliyyah of Engineering, International Islamic University Malaysia, Kuala Lumpur, Malaysia

${ }^{2}$ International Institute for Halal Research and Training (INHART), International Islamic University Malaysia, Kuala Lumpur, Malaysia

${ }^{3}$ Faculty of Bioresources and Food Industry, Universiti Sultan Zainal Abidin, Tembila Campus, 22200 Besut, Terengganu, Malaysia

Published online: 08 August 2017

\begin{abstract}
The aim of this study was to observe the effect of abiotic stress under light and dark conditions on pumpkin calluses carotenoid. Plant elicitors used to create abiotic stress in this study were Polyethylene Glycol 4000 for drought stress, Jasmonic Acid and Salicylic Acid for hormones stress and Murashige and Skoog Salt for control and half strength nutrients. Carotneoid content was determined using High Performance Liquid Chromatography. Under light condition, the value of lutein was in range $0.554 \pm 0.107 \mu \mathrm{g} / \mathrm{g}$ to $0.169 \pm 0.003 \mu \mathrm{g} / \mathrm{g}$ and $\beta$-carotene was in range of not detected up to $8.133 \pm 0.088 \mu \mathrm{g} / \mathrm{g}$. Differ to dark condition, a trace amount of lutein was detected in each treatments and the highest amount of $\beta$-carotene was detected in Polyethylene glycol treatment $(5.313 \pm 0.051 \mu \mathrm{g} / \mathrm{g})$. Carotenoid content varies in each treatment due to adaptation of pumpkin calluses with abiotic stress induced to them.
\end{abstract}

Keywords: cucurbita moshata; calluses; carotenoid; high performance liquid chromatography; lutein; $\beta$ carotene.

Author Correspondence, e-mail: norshazila@unisza.edu.my doi: http://dx.doi.org/10.4314/jfas.v9i2s.56 


\section{INTRODUCTION}

Carotenoids are accumulated in most plant organs and they are lipophilic secondary metabolites, which derived from the isoprenoid pathway. In plants, carotenoids are synthesized and localised in the plastids. Plastids may differentiate into several forms which normally consist of chloroplasts, chromoplasts, gerontoplasts and leucoplasts. Chloroplasts store carotenoids in thylakoid membranes while chromoplasts store high levels of carotenoids in membranes, oil bodies or other crystalline structures within the stroma [1].

In pumpkin, carotenoids are synthesized in chloroplast and chromoplast [2]. Chloroplasts are organelles, specialized subunits, in plant and algal cells and their main role is to conduct photosynthesis process while chromoplast is heterogeneous organelles which are responsible for pigment synthesis and storage in specific photosynthetic eukaryotes [3]. In chloroplasts, carotenoids constitute photosynthetic complexes in thylakoid membranes where the formation of thylakoid membranes is believed to promote sequestration and storage of the synthesized carotenoids for high level of accumulation in the chloroplasts. However, regulation of chromoplast biosynthesis plays a crucial role in controlling the carotenoid content in plants by enabling a great biosynthesis and high storage capacity [4-6].

Calluses are those cells that cover a plant wound and were generated from plant leaf cuttings. Plant calluses are usually derived from somatic tissues and the callus initiation process normally depends on the plant species and the plant tissues used for the plant culture. The cells that give rise to calluses and somatic embryos usually undergo rapid division or are partially undifferentiated such as meristematic tissue [7]. Studies on plant secondary metabolites using cell cultures have been increasing over the last 50 years [8].

In nature, environmental factors highly influenced the carotenoids content and composition in pumpkin flesh and these factors are difficult to control thus carotenoids content are varied quantitatively and qualitatively. However, certain parameters can be controlled and this can be conducted in laboratory. Biogenesis manipulation is one of the new approaches to manipulate and produce carotenoids compound. This approach used environmental stress as a tool to alter the carotenoid pathway in the plants or calluses. Thus, specific carotenoid can be produced either through enhancing or inhibiting effects caused by those treatments. In this study, plant 
elicitors which consist of Jasmonic Acid (JA), Salicylic Acid (SA), Polyethylene Glycol (PEG) and Half Strength (HS) under light and dark conditions were used as a tool of abiotic stress to observe the effect on carotenoids content in pumpkin calluses.

\section{RESULTS AND DISCUSSION}

Carotenoid content was measured quantitatively and qualitatively by using High Performance Liquid Chromatography (HPLC). To assure the correct determination of carotenoids, spectrum of carotenoid detected in each samples were observed based on the retention time (RT) and UV-VIS spectrum recorded by the standard. Fig. 1 and Fig. 2 show HPLC chromatogram of carotenoid content in pumpkin calluses in control treatment. Both Chromatogram shows that two types of carotenoid detected were lutein and beta carotene. For carotenoid content in abiotic stress treatments under light and dark condition is shown in Table 1.

Under light condition, there were significant difference of lutein compound detected in each treatment and the highest amount of lutein content was detected in control treatment $(0.554+$ $0.107 \mu \mathrm{g} / \mathrm{g}$ ). There were no significant difference between the highest amount of beta carotene detected in HS treatment $(8.133 \pm 0.088 \mu \mathrm{g} / \mathrm{g})$ and control treatment $(8.053 \pm 1.366 \mu \mathrm{g} / \mathrm{g})$. However there was a significant difference of beta carotene content detected in JA (1.776 \pm $0.026 \mu \mathrm{g} / \mathrm{g})$ treatment and PEG treatment $(7.049 \pm 0.046 \mu \mathrm{g} / \mathrm{g})$. Under dark condition, there was no significant difference of lutein content between all treatments except in JA treatment. The highest lutein content was detected in PEG treatment $(0.087 \pm 0.001 \mu \mathrm{g} / \mathrm{g})$ while the lowest was detected in JA treatment $(0.008 \pm 0.002 \mu \mathrm{g} / \mathrm{g})$. Differ to beta carotene under dark condition; there were no significant difference of beta carotene content in all treatments except in control and JA treatment. The highest beta carotene content detected was in PEG treatment $(5.313+0.051 \mu \mathrm{g} / \mathrm{g})$ and the lowest was detected in HS treatment $(0.186+0.014$ $\mu \mathrm{g} / \mathrm{g})$. 


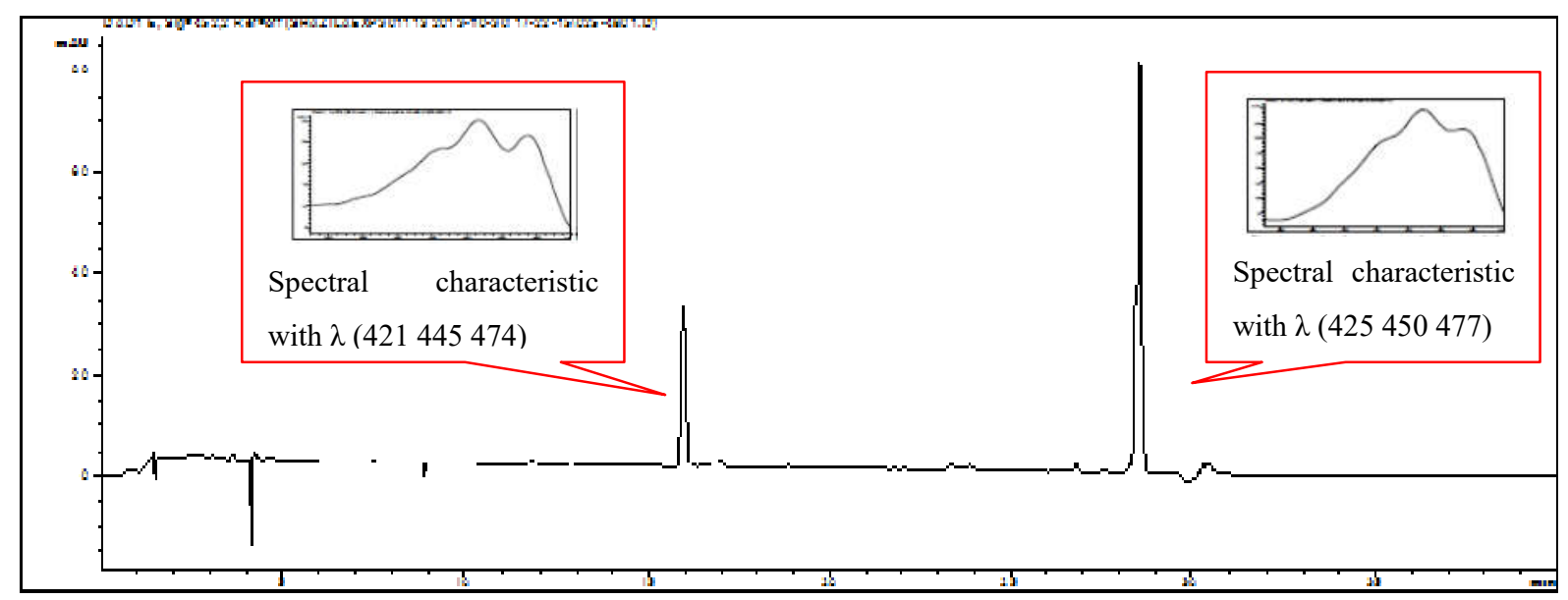

Fig.1. HPLC chromatogram of pumpkin callus under light condition (control treatment) RT: lutein-15.8 minutes (b) $\beta$-carotene-RT 29.3 minutes and their spectral characteristic [9]

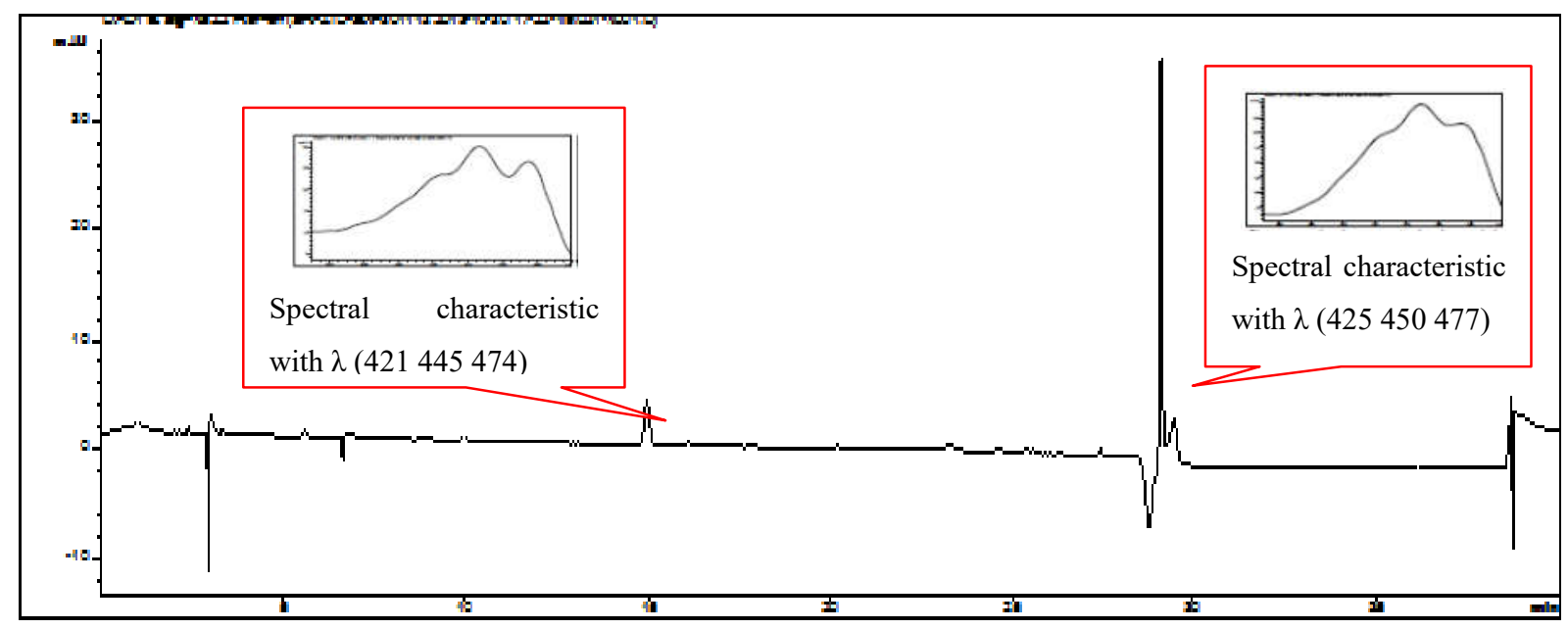

Fig.2. HPLC chromatogram of pumpkin callus under dark condition (control treatment) RT: lutein-15.8 minutes (b) $\beta$-carotene-RT 29.3 minutes and their spectral characteristic 
Table 1. Carotenoid content in pumpkin callus treated with plant elicitors under light and dark conditions

\begin{tabular}{ccccc}
\hline & \multicolumn{2}{c}{ Light } & \multicolumn{2}{c}{ Dark } \\
Treatments & Lutein & Beta Carotene & Lutein & Beta Carotene \\
& $(\mu \mathrm{g} / \mathbf{g})$ & $(\mu \mathrm{g} / \mathbf{g})$ & $(\boldsymbol{\mu g} / \mathbf{g})$ & $(\boldsymbol{\mu g} / \mathbf{g})$ \\
\hline Control & $0.554^{\mathrm{a}} \pm 0.107$ & $8.053^{\mathrm{a}} \pm 1.366$ & $0.039^{\mathrm{a}} \pm 0.003$ & $1.156^{\mathrm{a}} \pm 0.004$ \\
\hline SA & $0.078^{\mathrm{b}} \pm 0.007$ & $\mathrm{ND}$ & $0.048^{\mathrm{a}} \pm 0.001$ & $2.252^{\mathrm{c}}+0.013$ \\
JA & $0.073^{\mathrm{b}} \pm 0.002$ & $1.776^{\mathrm{b}} \pm 0.026$ & $0.008^{\mathrm{b}} \pm 0.002$ & $1.247^{\mathrm{a}}+0.127$ \\
PEG & $0.169^{\mathrm{c}} \pm 0.003$ & $7.049^{\mathrm{c}} \pm 0.046$ & $0.087^{\mathrm{a}} \pm 0.001$ & $5.313^{\mathrm{b}}+0.051$ \\
HS & $0.131^{\mathrm{c}} \pm 0.003$ & $8.133^{\mathrm{a}} \pm 0.088$ & $0.061^{\mathrm{a}} \pm 0.003$ & $0.186^{\mathrm{d}}+0.014$ \\
\hline
\end{tabular}

Means $(n=6)$ in the same column with different superscript are significantly $(p<0.05)$ different

ND: Not Detected

Control: Murashige Skoog Salt

The changes of carotenoid composition were complex and their responses to the plant elicitors used both in light and dark conditions clearly had significant impact to the carotenoid biosynthesis and accumulation in the pumpkin calluses. However, the mechanism was not well understood. Some hypotheses were made based on previous studies as well as observations found in this study. A summary of hypotheses is simplified as follows; H1). Each plant elicitor would alter the carotenoid metabolism pathway hence resulting in varied accumulation of carotenoid content, qualitatively and quantitatively, H2) SA and JA are hormone-like substances found naturally in plants. They are responsible for plant growth and development. By enhancing the media with these substances, two results would occur. They would either help in boosting or decreasing the yield of carotenoid, H3) SA and JA substances most likely retard or inhibit the growing process of pumpkin calluses due to the unsuitable conditions for them, H4) Drought stress caused by PEG 4000 would lead to abiotic stress which decreased the secondary metabolites yield including carotenoid in comparison to their potential yield in normal plants [28]. However, there were other studies that showed that carotenoid content was elevated by drought stress induced by PEG 4000 [31] and H5) 
Providing insufficient and inadequate nutrient (HS treatment) to the calluses would influence the photosynthetic electron transport system, thereby effecting the photosynthesis process [29]. As carotenoid is one of the main components that play an important role in the photosynthesis process, this compound would decrease under HS treatment. From all of the hypotheses mentioned above (H1-H5), the discussion shall be organized by subtopics as follows.

\subsection{Treatment with Salicylic Acid}

From the results obtained, only trace amount of lutein compound was detected in pumpkin calluses treated with SA under light condition and $\beta$-carotene compound was not detected. The calluses also turned into a brown colour as if they were dying and did not form well compared to the other pumpkin callus treatments. These observations were complied with hypotheses H1, H2 and H3. From these research findings, there were many factors that contributed to these circumstances.

Pumpkin calluses in this treatment probably were not resistant to the SA substance due to an unsuitable ratio used (H3), thus inhibiting the growth of the pumpkin calluses. Calluses may turn to brown colour and die during the culture period, but the causes for callus browning were not well understood [10]. In one study, it was mentioned that the higher concentration of SA used would lead to a decrease of cell cultures by about $20 \%$ to $35 \%$ [11].

From H3 hypothesis, oxidative stress caused by SA substance had caused the pumpkin calluses to die. Based on previous studies, SA substance could increase the superoxide dismutase (SOD) and peroxidase (POD) activities to protect plants from being injured [12-13]. In another study, browning calluses were observed to be high in polyphenoloxidase activities [14]. In response to abiotic and oxidative stress caused by SA substance, calluses formed in SA treatment turned into a brown colour, thus resulting in the negative response to the production on carotenoid yield ( $\mathrm{H} 1$ and $\mathrm{H} 2)$.

Aside from all the theories to answer the $\mathrm{H} 1, \mathrm{H} 2$ and $\mathrm{H} 3$ hypotheses, the pumpkin calluses probably died because of error in handling by the analyst. The error could occur during preparation of media as well as culturing the plant. However, the error caused by the analyst 
was not a concrete reason as the other pumpkin calluses in other treatments were successfully cultured and grown.

Different from light condition, treatment with SA under dark condition produced two times higher of $\beta$-carotene compound compared to the control (MS30) treatment. With the presence of abiotic stress caused by SA substance and very low light intensity under dark condition, SA substance with its ability to produce hormone-like properties is believed to produce more chlorophyll and photosynthetic apparatus to capture more light, thus resulted in an increasing amount of $\beta$-carotene compound in the treated pumpkin calluses $(\mathrm{H} 3)$. This indicates that abiotic stress induces gene expression related to biosynthesis of some classes of secondary metabolites in plants (including carotenoid biosynthesis) [15-16], thus resulted in the increasing yield of $\beta$-carotene compound in pumpkin calluses treated with SA under dark condition.

\subsection{Treatment with Jasmonic Acid}

In pumpkin calluses treated with JA under light condition, $\beta$-carotene content was found to be seven times lower than the $\beta$-carotene content from control (MS30) treatment which complied with H2 hypothesis. JA exhibits hormone-like properties that are responsible for plant growth and development. JA is also responsible for the aging of leaves by decreasing the chlorophyll content and it is related to the depression of the photosynthesis related gene. This circumstance was first reported based on the physiological effects of jasmonates group and the increase of JA level in aging leaves [17]. Not only promoting the aging of leaves, JA and its derivatives also induced aging in plant cell culture and excised leaves [18].

One study reported that these consequences were based on the studies done on excised or intact differentiated leaves after exogenous application of jasmonates [19]. This report was in line with the results obtained in this study. The decrease of carotenoid yield in pumpkin calluses treated with JA indicated that there was also a decrease in content of photosynthesis apparatus as mentioned above, as carotenoid was one of the main pigments that play important roles in the photosynthesis process.

There have been many reports on inhibition of carotenoid compound, especially lycopene compound due to the abiotic stress caused by jasmonic acids and its derivatives [20-21]. 
Regarding this circumstance, the presence of $\beta$-carotene compound can be correlated to the existence of lycopene compound as they are evolved from the same carotenoid pathways. Cyclization processes will transform lycopene to $\beta$-carotene, so inhibition of this compound will lead to decreased amounts of $\beta$-carotene as well [22].

In pumpkin calluses treated with JA under dark condition, the $\beta$-carotene yield was fairly consistent with the control (MS30) treatment. Me-JA (JA derivatives) inhibited chlorophyll accumulation at the level of chlorophyll precursors in the dark [23-24]. This could be one of the reasons why the amount of $\beta$-carotene content in pumpkin calluses in JA treatment under dark condition was fairly consistent with $\beta$-carotene content in control (MS30) treatment under the same conditions.

With the affects of chlorophyll inhibition and aging in pumpkin calluses, the yield of $\beta$-carotene compound produced under JA treatment in this study could be categorized as significantly low. Even though application of JA negatively affected the $\beta$-carotene yield in pumpkin calluses, this finding would benefit researchers in the carotenoid field. This information could be used to control or manipulate $\beta$-carotene production in the laboratory. This knowledge is also important for those who are involved in this area of research.

\subsection{Treatment with Polyethylene Glycol}

Under light condition, carotenoid content in pumpkin calluses treated with PEG 4000 was slightly lower than the control (MS30) treatment, which complied with H4 hypothesis due to the drought stress. PEG 4000 compound could not penetrate the cells as their molecules were bigger in size, but this compound will induce drought stress by restricting the water uptake [25]. This mechanism can be correlated to the inefficient of photosynthesis process due to the decreased of Photosystem II (PSII) activity. In PS II activity, specific intrinsic and extrinsic proteins were involved in the electron transport system. Under drought stress, oxygen-evolving capacity within the reaction centers were retarded [26]. Drought stress would induce a quantitative loss in the D1 protein, increased thylakoid lipid peroxidation and a decrease of $\beta$-carotene which plays an important role in protecting isolated PS II reaction centers from photoinhibition damage [10, 27]. 


\subsection{Treatment with Half Strength}

Under light condition, pumpkin calluses treated with HS of MS30 provided the highest yield of $\beta$-carotene, which was slightly higher than the control (MS30) treatment. In this study, $\beta$-carotene content detected in pumpkin calluses treated with HS under light condition gave no significant impacts on the secretion of their secondary metabolites under light condition. These findings contradict with the report given by [11], as mentioned in the hypothesis above (H5).

This indicated that adequate nutrient (HS) and light supplied to pumpkin calluses under light condition was sufficient for the calluses to grow and produce their secondary metabolites as in normal condition provided by the control (MS30) treatment. The amount of nutrients required for successful culture varies with genotype and species and is probably reflected by the synthetic capacity of the plant [25]. There was a study reported that the callus of Pinus strobus grew best when the level of inositol in MS0 medium was reduced to $50 \mathrm{mg} / \mathrm{l}$, whereas that of P. echinata. proliferated most rapidly when no inositol was present [30].

However, under dark condition, with half strength of nutrients and no lights supplied to the pumpkin calluses, the amount of $\beta$-carotene compound detected was ten times lower than the control (MS30) treatment. This was in line with a previous study conducted by [12] and also complied with the H5 hypothesis. This indicated that $\beta$-carotene content produced in pumpkin calluses with HS treatment under dark condition was significantly low due to the insufficient nutrients and light intensity for photosynthesis process to occur.

\subsection{EXPERIMENTAL}

\subsection{Callus Initiation}

Callus initiation was conducted as described by [12] with minor modifications. Media of tissue culture was prepared as follows; $4.4 \mathrm{~g}$ of MS0 salt was weighted in weighing boat and 1 liter of distilled water was mixed in Schott bottle. The $\mathrm{pH}$ of the mixture was adjusted to 5.6-5.8. After the adjusted $\mathrm{pH}$ was obtained, $1 \mathrm{ml} / 1$ of Biphenyl Amino Pureen and $2 \mathrm{ml} / 1$ of Naphtalenic Acetic Acid was added followed with $30 \mathrm{~g}$ of sucrose and stirred until the solution become homogeny. After that, $3.5 \mathrm{~g}$ of gelrite was added into the media. Then, the 
mixture was sterilized in the autoclave machine $\left(15\right.$ minutes, $\left.121^{\circ} \mathrm{C}\right)$. The sterilized agar was poured in glass jam jars and was left in laminar air flow until the agar becomes hard.

By conducting the sterilization technique to culture the pumpkin seeds, the procedure begins with washing the pumpkin seeds with sterile distilled water until the seeds were clean. Then, the pumpkin seeds were washed with $70 \%$ alcohol solutions for three to five minutes and re-washed with distilled water for 3 times. By using a sterilized spatula, the seeds (5 to 10 seeds/bottle) were placed on the prepared agar in the glass jam jars; the glass jam jars were covered with the plastic cover, sealed with parafilm and placed on a rack in the culture room under a lamp to provide them light day and night with temperature $20^{\circ} \mathrm{C}$ in the culture room. The pumpkin seeds culture was observed daily to ensure that there was no contamination during the culture period.

After 3 weeks, the pumpkin plants were ready for callus initiation in a different media. Leaves and stems of pumpkin plants were cut into small pieces and placed on the new media. After one month, the pumpkin calluses were observed. The pumpkin calluses were considered good if they grew without any shoots or roots during the growing period. The plant elicitors used for pumpkin calluses were as follows; i) MS30: $4.4 \mathrm{~g} / 1$ (Control), ii) Salicylic acid: $0.1 \mathrm{~g} / 1$ (SA), iii) Jasmonic Acid: 0.1 g/l (JA), iv) Polyethylene glycol: 5 g/l (PEG) and iv) Half strength: MS15, $2.2 \mathrm{~g} / 1$ (HS).

Each of the treatments were conducted under a light versus darkness by incubation under cool-white, fluorescent lamps $\left(80-85 \mu \mathrm{mol} \mathrm{m} \mathrm{m}^{-2} \mathrm{~s}^{-1} ; 24\right.$ hours photoperiod) and with dark condition imposed by carefully covered the pumpkin plants and calluses in a sealed card box. After the treatment period for 2 weeks, the pumpkin callus were observed, harvested and extracted for carotenoid analysis.

\subsection{Preparation of Sample}

Pumpkin calluses were harvested after 2 weeks of treatments and freeze dried. The freeze dried calluses were grounded into powder form prior to extraction.

\subsection{Extraction}

The extraction procedure described by [12] was followed with slight modifications. $1 \mathrm{~g}$ of powdered freeze-dried calluses was weighed and mixed with $5 \mathrm{ml}$ acetone and methanol 
mixture $(7: 3 ; \mathrm{v} / \mathrm{v})$ in a centrifuge tube. To allow efficient solvent penetration, the mixture was vortexed and allowed to stand overnight in darkness at room temperature. The next day, the samples was re-vortexed and centrifuged for 15 minutes at $13500 \mathrm{~g}$ (Sorvall Biofuge Primo R, Thermo Scientific). Then, the supernatant was transferred into a new $50 \mathrm{ml}$ centrifuge tube. This procedure was repeated for three times until the tissue turned coluorless. Extraction was continued by adding an equal volume of $15 \mathrm{ml}$ of hexane and $15 \mathrm{ml}$ of distilled water to the combined supernatants. The solution was then centrifuged for 15 minutes at $13500 \mathrm{~g}$ to allow better separation. The upper hexane layer containing the carotenoids was collected and dried under the nitrogen gas. Vials/tubes then were capped and sealed with parafilm to exclude oxygen and was immediately stored at $-20^{\circ} \mathrm{C}$ for further analysis.

\subsection{Saponification}

Saponification was done as described by [12] with slight modifications. Carotenoid extract which was dried after the extraction process was then subjected to certain steps. $20 \mu 1$ of acetate were added into the samples, followed with $380 \mu$ l acetonitrile: distilled water $(9: 1, \mathrm{v} / \mathrm{v})$. Then, $400 \mu 1$ methanolic potassium hydroxide solutions $(10 \% ; \mathrm{w} / \mathrm{v})$ was added. Base carotenoids were then extracted by addition of $2 \mathrm{ml}$ hexane with $0.1 \%$ butylated hydroxytoluene (BHT), followed with $10 \%$ of sodium chloride $(\mathrm{NaCl})$. Finally, the extracts were washed with distilled water, the upper layer was collected and dried under a gentle stream of oxygen-free nitrogen and re-suspended in ethyl acetate for HPLC analysis.

\subsection{High Performance Liquid Chromatography (HPLC) Analysis}

The HPLC analysis of carotenoids was performed using Agilent model 2100 series which comprises of a binary pump with auto sampler injector, micro vacuum de-gassers, thermostat column compartment and a diode array detector. The column that used was a HPLC column: ZORBAX Eclipse XDB-C18, analytical 4.6 x $150 \mathrm{~nm}$ (5 micron) end capped $5 \mu \mathrm{m}$. The solvents used were (A) acetonitrile: water (9:1 v/v) and (B) ethyl acetate. The solvent gradient used was developed as follows: $0-40 \%$ solvent B (0-20 minutes), $40-60 \%$ solvent B (20-25 minutes), 60-100\% solvent B (25-25.1 minutes), 100\% solvent B (25.1-35 minutes) and 100-0\% solvent $\mathrm{B}$ (35-35.1 minutes) at a flow rate of $1.0 \mathrm{ml} \mathrm{min}^{-1}$. The temperature of the column was maintained at $20^{\circ} \mathrm{C}$. 
The injection volume was $10 \mu$ l. Carotenoid standards of $\beta$-carotene and lutein was obtained commercially from Sigma-Aldrich. Detection for carotenoid peaks was in the range of 350 to $550 \mathrm{~nm}$. Individual carotenoid concentrations were calculated by comparing their relative proportions, as reflected by the integrated HPLC peak areas.

\subsection{Statistical Analysis}

The statistical analysis was conducted using SPSS. All the data were reported as mean \pm standard deviation using One-Way ANOVA method. The significance difference among the samples were compared using Duncan multiple test at significance level $(p<0.05)$.

\section{CONCLUSION}

From this study, abiotic stress using plant elicitors under light and dark conditions could enhance and inhibit carotenoid content in pumpkin calluses. In vitro system used in this study gives many advantages such as a controlled environment system to manipulate the carotenoid biosynthesis pathway. However, for a better understanding, further studies should be conducted to investigate the mechanism involved in the biogenesis manipulation in this study more thoroughly.

\section{ACKNOWLEDGEMENTS}

We would like to thank Herbarium Lab, International Islamic University Malaysia for the facilities provided and University Sultan Zainal Abidin for the financial support.

\section{REFERENCES}

[1] Howitt C A, Pogson B J. Carotenoid accumulation and function in seeds and non-green tissues. Plant, Cell and Environment, 2006, 29(3):435-445

[2] Wrischer M, Devide Z V. Chromoplasts-The last stages in plastid development. International Journal of Developmental Biology, 2002, 35(3):251-258

[3] Whatley J M, Whatley F R. When is a chromoplast? New Phytologist, 1987, 106(4):667-678

[4] Lu S, Li L. Carotenoid metabolism: Biosynthesis, regulation, and beyond. Journal of 
Integrative Plant Biology, 2008, 50(7):778-785

[5] Cazzonelli C I, Pogson B J. Source to sink: Regulation of carotenoid biosynthesis in plants. Trends in Plant Science, 2010, 15(5):266-274

[6] Ruiz-Sola M Á, Rodríguez-Concepción M. Carotenoid biosynthesis in Arabidopsis: A colorful pathway. The Arabidopsis Book, 2012, 10:1-29

[7] Wang X D, Nolan K E, Irwanto R R, Sheahan M B, Rose R J. Ontogeny of embryogenic callus in Medicago truncatula: The fate of the pluripotent and totipotent stem cells. Annals of Botany, 2011, 107(4):599-609

[8] Mok M C, Gabelman W H, Skoog F. Carotenoid synthesis in tissue cultures of Daucus Carota L. Journal of the American Society for Horticultural Science, 1976, 101:442-449

[9] Rodriguez-Amaya D. B. A guide to carotenoid analysis in foods. Washington DC: International Life Sciences Institute Press, 1999

[10] Yokoi S, Bressan R A, Hasegawa P M. Salt stress tolerance of plants. JIRCAS Working Report, 2002, 23(1):25-33

[11] Sudhir P R, Pogoryelov D, Kovacs L, Garab G, Murthy S D. The effects of salt stress on photosynthetic electron transport and thylakoid membrane proteins in the cyanobacterium Spirulina platensis. BMB Reports, 2005, 38(4):481-485

[12] Rashidi O. Biochemistry and genetics of carotenoid composition in potato tubers. Phd thesis, England: Lincoln University, 2009

[13] Shi Q, Zhu Z. Effects of exogenous salicylic acid on manganese toxicity, element contents and antioxidative system in cucumber. Environmental and Experimental Botany, 2008, 63(1):317-326

[14] Tang W, Newton R J. Increase of polyphenol oxidase and decrease of polyamines correlate with tissue browning in Virginia pine (Pinus virginiana Mill.). Plant Science, 2004, 167(3):621-628

[15] Schenk P M, Kazan K, Wilson I, Anderson J P, Richmond T, Somerville S C, Manners J M. Coordinated plant defense responses in Arabidopsis revealed by microarray analysis. Proceedings of the National Academy of Sciences, 2000, 97(21):11655-11660

[16] Taguchi G, Yazawa T, Hayashida N, Okazaki M. Molecular cloning and heterologous 
expression of novel glucosyltransferases from tobacco cultured cells that have broad substrate specificity and are induced by salicylic acid and auxin. FEBS Journal, 2001, 268(14):4086-4094

[17] He Y, Fukushige H, Hildebrand D F, Gan S. Evidence supporting a role of jasmonic acid in Arabidopsis leaf senescence. Plant Physiology, 2002, 128(3):876-884

[18] Creelman R A, Mullet J E. Jasmonic acid distribution and action in plants: Regulation during development and response to biotic and abiotic stress. Proceedings of the National Academy of Sciences, 1995, 92(10):4114-4119

[19] Weidhase R A, Lehmann J, Kramell H, Sembdner G, Parthier B. Degradation of ribulose-1, 5-bisphosphate carboxylase and chlorophyll in senescing barley leaf segments triggered by jasmonic acid methylester, and counteraction by cytokinin. Physiologia Plantarum, 1987, 69(1):161-166

[20] Saniewski M, Czapski J. The effect of methyl jasmonate on lycopene and $\beta$-carotene accumulation in ripening red tomatoes. Cellular and Molecular Life Sciences, 1983, 39(12):1373-1374

[21] Liu L, Wei J, Zhang M, Zhang L, Li C, Wang Q. Ethylene independent induction of lycopene biosynthesis in tomato fruits by jasmonates. Journal of Experimental Botany, 2012, 63(16):5751-5761

[22] Rodriguez-Amaya D. B., Kimura M. HarvestPlus handbook for carotenoid analysis. Washington DC: International Food Policy Research Institute, 2004

[23] Poonam S, Kaur H, Geetika S. Effect of jasmonic acid on photosynthetic pigments and stress markers in Cajanus cajan (L.) Millsp. seedlings under copper stress. American Journal of Plant Sciences, 2013, 4(4):817-823

[24] Ananiev E D, Ananieva K, Todorov I. Effect of methyl ester of jasmonic acid, abscisic acid and benzyladenine on chlorophyll synthesis in excised cotyledons of Cucurbita pepo (Zucchini). Bulgarian Journal of Plant Physiology, 2004, 30(1-2):51-63

[25] George E. F., Hall M. A., De Klerk G. J. Plant propagation by tissue culture: Volume 1-The background. Berlin: Springer Science and Business Media, 2007

[26] Eastman P A, Rashid A, Camm E L. Changes of the photosystem 2 activity and thylakoid 
proteins in spruce seedlings during water stress. Photosynthetica, 1998, 34(2):201-210

[27] Deo P M, Biswal B. Response of senescing cotyledons of clusterbean to water stress in moderate and low light: Possible photoprotective role of $\beta$-carotene. Physiologia Plantarum, 2001, 112(1):47-54

[28] He Y, Guo X, Lu R, Niu B, Pasapula V, Hou P, Cai F, Xu Y, Chen F. Changes in morphology and biochemical indices in browning callus derived from Jatropha curcas hypocotyls. Plant Cell, Tissue and Organ Culture, 2009, 98(1):11-17

[29] Gadzovska S, Maury S, Delaunay A, Spasenoski M, Hagège D, Courtois D, Joseph C. The influence of salicylic acid elicitation of shoots, callus, and cell suspension cultures on production of naphtodianthrones and phenylpropanoids in Hypericum perforatum L. Plant Cell, Tissue and Organ Culture, 2013, 113(1):25-39

[30] Kaul K, Kochhar T S. Growth and differentiation of callus cultures of Pinus. Plant Cell Reports, 1985, 4(4):180-183

[31] Mutlu S, Atici Ö, Nalbantoglu B. Effects of salicylic acid and salinity on apoplastic antioxidant enzymes in two wheat cultivars differing in salt tolerance. Biologia Plantarum, $2009,53(2): 334-338$

\section{How to cite this article:}

Shahidan N, Othman R, Jaswir I, Hasyun-Hashim Y Z. Effect of Abiotic Stress under Light and Dark Conditions on Carotenoid Content in Pumpkin (Cucurbita moshata) Calluses. J. Fundam. Appl. Sci., 2017, 9(2S), 861-875. 